Adam Sofronijević1, Vesna Milićević ${ }^{2}$, Aleksandar Marković ${ }^{3}$

${ }^{1}$ University of Belgrade, University Library „Svetozar Marković” 2,3 University of Belgrade, Faculty of Organizational Sciences, Serbia

\title{
New Internet Business Initiatives in the Context of Change Management
}

\author{
UDC: 005.336.5:004 \\ 004.738 .5 \\ 005.591:005.21 \\ DOI: 10.7595/management.fon.2015.0007
}

\begin{abstract}
The paper presents the changing role of the Internet as a framework of several new business initiatives. In the last five years the Internet has evolved from being just a useful tool to a force shaping business strategies and influencing long-term managerial decision making. The paper presents an analysis of several cutting edge business initiatives and relates the success opportunities they have with evolving features of the Internet. The growth of importance of the Internet stresses the need to evaluate the state of local ICT development and precise data in this area for successful new business initiatives and meaningful change management. The paper presents the importance of such an evaluation for engaging change management that may be the crucial factor for the future of business initiatives in the era of ubiquitous, smart Internet.
\end{abstract}

Keywords: Internet Business, Digital Business Strategy, Change Management, Internet of Things-based Business Ecosystem, Information and Communication Technologies.

\section{Introduction}

The Internet has been changing since its inception and as its ubiquity rises, these changes affect a growing number of industries and human activities. Change management techniques thus become a standard piece of managerial equipment in the toolbox of successful managers. Furthermore, the importance and omnipresence of the Internet in contemporary business environment is such that it becomes an important strategic factor and not just merely another communication medium or channel of distribution. Factoring in the influence and the role of the Internet in new business ventures is a must for a successful conduct of business operations in almost every industry today. The planning and control of new business initiatives that are primarily based on the Internet have to comprise many aspects of change management having in mind the high level of change rate affecting both the Internet as an entity and its particular instances, especially those business oriented.

Many new features of the Internet emerge, but it seems that the most important trends affecting it today are related to the concept of loT - Internet of Things, an omnipresent and highly networked environment comprising a multitude of seemingly intelligent independent agents running everything, from fridges and cars to temperature sensors and wallets. The emergence of big data, virtual currencies and goods, even envisioning of property independence and group self renewal for machines puts change management in the hot spot of managerial attention as it transitions from peak to everyday management activity. Thus its constant evaluation becomes a very important task that provides one of the major inputs for planning and execution of new business initiatives based on the Internet. 


\section{Digital Business Strategy and Internet Challenges}

When planning new Internet business initiatives managers need to factor in the strategic importance and the changing nature of the Internet. More broadly, both the Internet and other information and communication technologies are becoming so crucial for business that strategies related to them are not perceived as functional strategies that need to be aligned with the business strategy, but merge with them into one digital business strategy that encompasses elements of both and reflect the importance of IT in contemporary business (Bharadwaj, et al., 2013). In order to better analyse this new environment and help the next generation get insights into business and information-related decision making four themes of key importance for digital business strategy have been identified along with the drivers behind them (Figure 1).

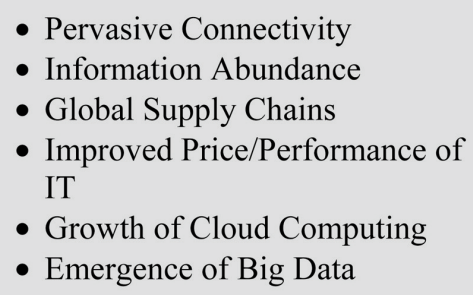

- Pervasive Connectivity

- Information Abundance

- Global Supply Chains

- Improved Price/Performance of IT

- Growth of Cloud Computing

- Emergence of Big Data

- Limitations of Traditional Business Models

- Trans-functional Role for IT

- New Mandate for IT and the $\mathrm{CIO}$

- Increased Familiarity with IT
- Scope of Digital Business Strategy

- Scale of Digital Business Strategy

- Speed of Decision Making

- Sources of Value Creation and

Figure 1: Drivers of the Four Key Themes of Digital Business Strategy,

(Bharadwaj, et al. 2013, p. 473)

The scope of digital business strategy extends beyond that of traditional business strategy and into the domain of dynamic ecosystems that span industries. Major digital ecosystems based around operating systems such as iOS or Android provide basis for the development of new products and services that may be delivered both in physical an virtual worlds. When considering the scale of digital business strategy one needs to address the scale in both physical and digital terms having in mind information abundance as one of the key environmental factors. The speed of business-related developments can be analyzed regarding the following dimensions (Bharadwaj, et al. 2013):

- speed of product launches,

- speed of decision making,

- speed of supply chain orchestration

- speed of network formation and adaptation.

All these four elements reflect changing realities of the Internet driving continuous activities around the globe and the utmost need to consider the timeframe of business operations as a crucial factor for their success. Finally, value creation is ever more dependant and embedded in information and the Internet, not just as a highway for information, but its changing features represent crucial information for many business operations today.

Important business vector that adds to increasing the rate of Internet change is a specific way of growth of major companies shaping the Internet and general global environment such as Apple, Google, Microsoft, 
Facebook, Amazon and Samsung. The evolutionary way of development of these companies in the framework of their respective ecosystem created by ubiquitous Internet and availability of services, devices, apps and content provided by these companies give rise to new business behavior models such as these in the areas of patents (Gómez-Uranga, et al., 2014). Acquisition of patent portfolios and patent lawsuits for infringements and violations reflect a fierce competition between major businesses shaping the contemporary Internet and at the same time the need for collaboration and enlarging targeted audiences and markets create new dynamics of business groups.

Companies developing new business activities based on technologies foremost of which are Internet related are under heavy pressure of competition and pace of innovation coming from globalized markets. For such companies, strategic decision making and growth are related and intertwined with the processes of internationalization, innovation and entrepreneurship placing the new multidisciplinary Internet-related field of research and business practice as the key to success of business (Onetti, et al. 2012).

Nowadays, the Internet of Things - loT is in the center of analysis and attention of many industries and of academia worldwide. Although the phrase was coined in 1999 (Ashton, 2009) only the recent breakthroughs in different digital technologies allowed for it to increasingly become an important part of business environment. The loT as a new instigation of the Internet is a major force in contemporary business environment. By the end of this year, 2015, over 25 billion various digital devices and gadgets will be connected via the Internet and this number will double to 50 billion units by 2020 (Cisco, 2011). The value of loT related business is assessed at $\$ 14.4$ trillion (Cisco, 2011) and the additional impact on other industries will be worth $\$$ 6.2 trillion by 2025 (McKinsey, 2013).

The emergence of the loT changes the business environment in such a way that new concepts are needed to replace the outdated ones. One such concept is business ecosystem in the $6 \mathrm{C}$ framework (Rong, et al., 2015). Within this concept three patterns of the development of business ecosystems have been identified (Figure 2). In order to better understand these patterns that are of utmost importance as they model possibilities for future new Internet business initiatives the dimensions of $6 \mathrm{C}$ framework need to be explained in some detail:

- Context dimension defines the environmental features of a supply network in the ecosystem helping researchers and practitioners understand why and how driving forces, main barriers and key missions arise in this area.

- Construct dimension deals with the fundamental structure and supportive infrastructure of a business ecosystem and provides answers on how to better utilize the ecosystem infrastructure for the purpose of achieving business aims.

- Configuration dimension researchers and practitioners may seek to identify the external relationships among partners in the business ecosystem and its configuration patterns.

- Cooperation dimension is about mechanisms of partner interaction aimed at achieving common strategic goals.

- Capability dimension is about analyzing the key success features of a supply network and describing the functioning of design, production, inbound logistics and information management in order to explain why some supply networks are better than the others.

- Change dimension describes the system configuration pattern shifts within business ecosystems and the resulting change affecting business decision making.

Having all this in mind one can conclude that business ecosystems based on the loT are more than just a set of connected items providing supply functions for the business. They seem to be evolving into complex networks comprising various stakeholders who provide their specific contribution to achievement of shared strategic business goals and this contribution and changing patterns of inter-partner relations shape the evolution of such business ecosystems. 


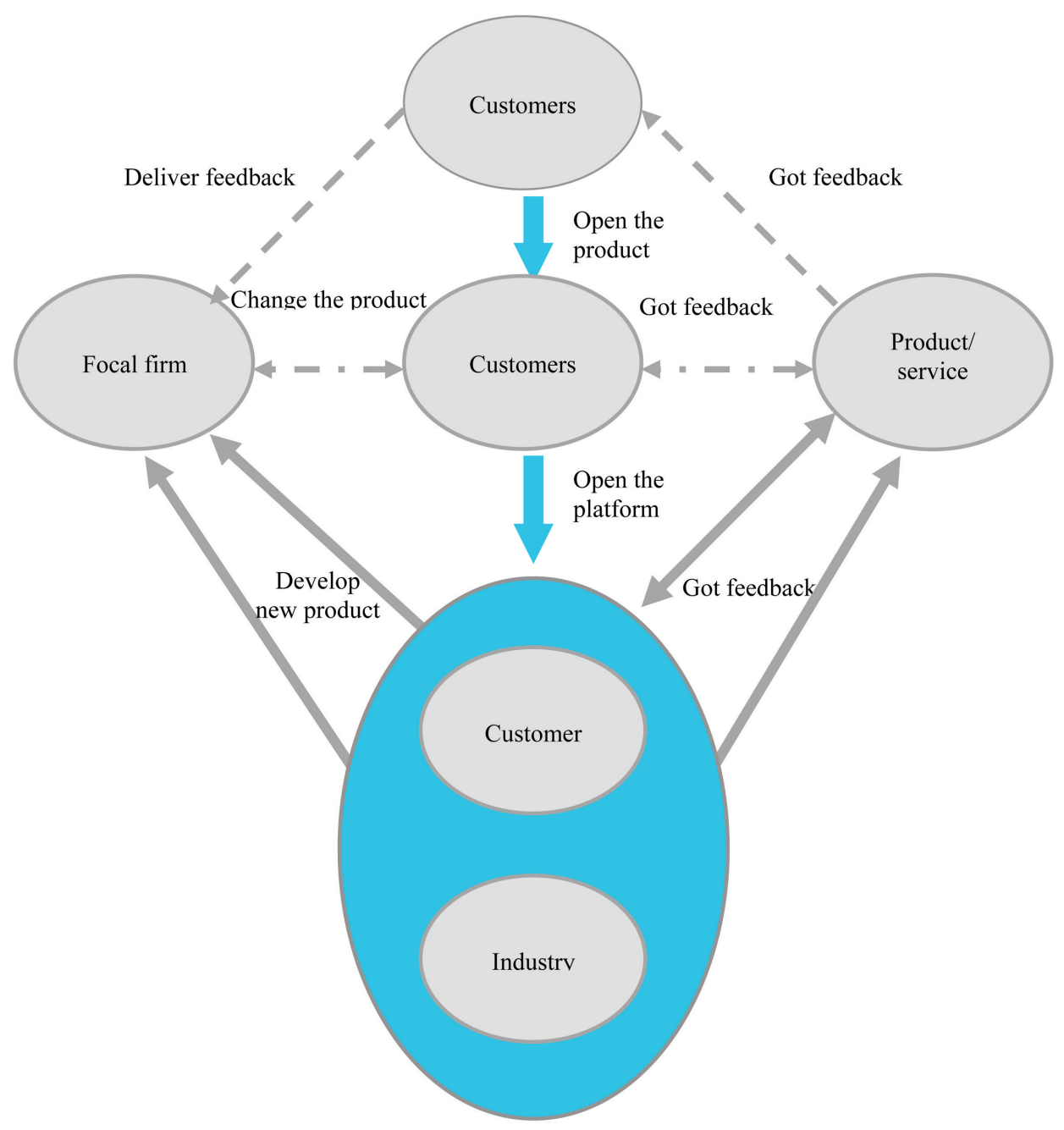

Figure 2: Three patterns of the loT-based business ecosystem,

(Rong, et al., 2015, p. 51)

One of the underlying technologies that provide possibilities for the omnipresence of the loT is that of wireless mobile communication, at the moment transitioning from its $4 G$ to $5 G$ instigation. As the Internet changes so does the role and significance of the supporting infrastructures. The importance of landlines in the early Internet has been replaced by infrastructures basically developed for delivering a cable TV signal. And while ever more users are cutting the cords nowadays, changes to wireless mobile infrastructures are analyzed to allow them to meet the demands, all these envisioned the loT beyond 2020. In the last two years the speed of development of ideas and research projects regarding envisioned $5 \mathrm{G}$ standard for wireless mobile communication technology has been increasing. This seems to be pushed in main part by the need to provide a more reliable and efficient infrastructure for the emerging loT. 5G networks are planned to allow for tens of billions devices to be connected worldwide in a sustainable and efficient way. Green and soft are becoming code words for making the wireless mobile network operational in the framework of expectations of businesses and governments. In this regard a proposition for the following five interconnected areas of research has been made (Chih-Lin, 2014):

- energy efficiency and spectral efficiency co-design,

- no more cells,

- rethinking signalling/control,

- invisible base stations, and

- full duplex radio. 
In order to illustrate further challenges and possibilities evolving around new Internet business initiatives we will provide a short description of some aspects of several such initiatives based on the loT. One important factor affecting contemporary business is the environment and rules and regulations put in place to balance the need for industries' growth with its sustainability i.e. environment fit for living. The problem of collecting data on environment change is complex since it requires many different inputs and specific measurements and evaluations in order not to err either on the side of growth or on long-term sustainability. To cope with such a complex task a novel integrated information system that combines the Internet of Things, the Cloud Computing, remote sensing, the geographical information system, the global positioning system and e-Science for environmental monitoring and management has been proposed, set up and tested in a case study of the Chinese province of Xinjiang (Fang, 2014). This experience proved that the main benefits in such a scenario come from data collection supported by the loT, Web services and applications based on cloud computing and e-Science platforms. The appropriate application of changed Internet features helped improve the effectiveness of monitoring processes and the decision-making in a vital area of evaluation of industries' effects on the environment.

The Internet of Things provides a wide range of opportunities for industrial deployment across different industries and in all areas of management functions. A novel solution based on this new, changing Internet has been proposed in the area of decentralized management of warehouses (Reaidy, Gunasekaran, \& Spalanzani, 2015). The loT provides infrastructure for collaborative warehouse order fulfillment based on RFID (Radio frequency identification), ambient intelligence and a multi-agent system comprising physical devices layer, a middleware platform and enterprise resource planning functions. An especially interesting feature of this solution is an integration of a bottom-up approach with decision support mechanisms and implementation of self-organization and negotiation protocols between agents. This builds a basis for independent or semi-independent ecosystem of warehouses providing for any given industry that requires goods stored in such a warehouse system. Competition, self renewal and growth of warehouse ecosystems that may emerge based on such proposed model should be beneficial for globalized business initiatives and interrelations established through the Internet may provide for more efficient and resilient knowledge based economies.

The omnipresence and high speed rates of data transfer are important characteristics of the Internet that affect advertising and marketing. The 3D virtual advertising is an emergent field that changes both the quality and quantity of advertisement business and marketing strategies of companies. Vividness of mental imagery provided for customers in an online shopping environment gave rise to further intertwining of physical and virtual business environments by allowing a need for touch to be translated into virtual by persuasive 3D imagery. Early research indicates that $3 \mathrm{D}$ advertising outperforms $2 \mathrm{D}$ advertising in effectiveness and constitute an important new element in Internet business projects related to advertisement (Choi, \& Taylor, 2014).

High speed rates of data transfer combined with 3D printing technology give rise to a new phenomenon related to the Internet: a possibility to transfer physical objects from the Internet and virtual domain back to physical world. This transformation of intangible services provided so far though the Internet to tangible goods available for consumption in all richness of their physical aspects may be another revolutionary feature of a changing Internet and certainly a major force that changes the Internet and has to be factored in when contemplating new business initiatives based on the Internet. Such is the potential importance of this new development that even a name for a new phase of Internet development has been coined - Internet of the 3D Printed Products (Kaur, 2012).

Creative, innovative, new business initiatives are nowadays almost always related to the Internet. Thus the sheer availability of the Internet is an important factor when planning such initiatives. In many regions globally this first feature - availability of the Internet has been fulfilled, so more complex evaluations are needed and they are inevitably followed by the evaluation of more general ICT development features that made the use of Internet based business opportunities and consumption of services offered through the Internet effective and efficient. The complexity of the Internet and related ICT developmental features makes a straightforward evaluation not-efficient and imply more sophisticated means of evaluation and measuring tools. One such useful tool is the ICT development index (IDI) which provides a combination of different input values for assessing a country level of development as regards ICT. The ICT Development Index is a composite index combining 11 indicators bearing different fixed weights into one benchmark measure that serves to monitor and compare developments in information and communication technology across countries (International Telecommunication Union, 2014). The IDI was developed by International Telecommunication 
Union - United Nations specialized agency for information and communication technologies in 2009 and is widely used since. Three major indicator groups of the IDI that encompass 11 indicators are: ICT access, ICT use and ICT skills.

Another more sophisticated measuring approach to evaluation of ICT development has been proposed recently. The I-distance method combines 11 indicators used by the IDI, but in a flexible order allowing for specifics of a country environment and development stage to be focused on (Dobrota, Jeremić, \& Marković, 2012). Thus more relevant results for developing and transitional countries are achieved.

As regards the I-distance rank, it may be very useful in assessing new business opportunities and initiatives related to Internet. For example, the more important factors when considering the described system of decentralized management of warehouses belong to ICT Access indicator groups since the possibility to connect a warehouse into the system depends primarily on the Internet availability. On the other hand, in case we need to assess prospects of the successful implementation of the Internet-based parent training for children with conduct problems, the ICT Skills indicator group is crucial. In order to measure the optimal influence of ICT development on a certain new Internet business initiative, a sophisticated method for determining weights of indicators needs to be developed that will include specifics of the particular country and of the particular Internet-related business initiative. Such a measurement tool may be very effective in assessing chances for success in planning phases of such ventures. Having in mind the scope of global business activates and the need to expand to as many markets as possible with as little resources needed, optimizing business inputs for certain markets may be crucial for successful operations of companies in the future. Finally, an important aspect of such proposed measuring tool is its flexibility. The Internet is changing and so is the level of ICT development of certain countries, so after certain threshold is reached, new indicators gain more importance and others lose it. Therefore if a precision mechanism for determining weights of indicators is in place, such changes may be dynamically and automatically registered and a flag may be raised for management to decide if the time has come to involve another country and a new market in a certain business initiative. This may be of great value for multi project management and companies that are running many simultaneous Internet-related business initiatives, and the general prospects of globalized world market and dynamic development of business environment are such that the proposed scenario for running business operations of a company is relevant including running the great number of small scale Internet business initiatives globally.

\section{The Importance of Change Management for New Internet Business Initiatives}

The successful management of change is crucial for any organisation envisioning new Internet business initiatives. It is also a sine qua non for survival and success in the present highly competitive and continuously evolving business environment. There are many different modes of change in contemporary business; some are characterised by the frequency of change and others by the nature of how change comes about (Todnem By, 2005, as in Table 1).

Table 1 Types of changes in contemporary business, adapted from (Todnem By, 2005, p. 371)

\begin{tabular}{|c|c|c|}
\hline $\begin{array}{l}\text { Type of change } \\
\text { defined by }\end{array}$ & frequency of change & how change comes about \\
\hline & Discontinuous change & Planned \\
\hline & Incremental change & Emergent \\
\hline & Bumpy incremental change & Contingency \\
\hline & Continuous change & Choice \\
\hline
\end{tabular}


It would be best if a new Internet business initiative is planned and executed in the organised manner of planned change. On the other hand, it is often the case the changes related to ongoing Internet related business are emergent and not planned very well or present themselves as a contingency to a sudden new business situation most often prompted by a changing nature of the Internet. The alternative is to have the change in the ongoing Internet-related business as a planned and informed choice based on a thorough analysis of the Internet and related environmental changes. Discontinuous approach to change is often presented though it does not seem to provide lasting business results. Opposition to this kind of change is a continuous change requiring much more resources for continuing monitoring and analysis of the Internet trends and related consequences in user behaviour and expectations, but providing a solid base for longterm positive business results. Continuous change describes organisation-wide changes often related to strategies, that suit well with strategic shifts of Internet change such as emergence of the loT. Incremental change describes departmental or operational changes that fit with day to day changes of the Internet such as appearance of a new service based on the existing technology or of new content that is important either in size or quality.

There are two areas of Internet-related business operations where change management is of especially high importance. One is related to complex unstructured business situations where complexity arises in a number of possible options in business decision making that are based in numerous elements affecting business operations of an organization. A typical environment for such a scenario is a contemporary urban framework characterised by intertwining of numerous human and technology related issues and where complexity is amplified by dense population, multicultural context and complexity of relations between elements and entities important for business. Such environment is best described by a smart city concept and change management needs to be employed with special scrutiny and elaborate planning when conducting business in such areas (Sofronijević, Milićević, \& Ilić, 2014). The other area where change management plays an especially important part in managing the Internet-related business initiative is the one in which highly unstructured nature of environment and business elements emerge from complete novelty and a complex nature of employed technologies and various social, cultural and other implications that are not directly related to business itself. One example of such an area is coming from the domain of automation of intellectual jobs (Sofronijević, Milićević, \& llić, 2013). With many different new aspects affecting work processes traditionally performed by humans and by leaving even highly qualified humans jobless, such areas are related to meticulous managerial planning under conditions of continuous change.

Service-Oriented Computing (SOC) prompted many changes in many sectors, but the overall effect was such that business organizations got the chance to deliver their functionalities via Web services. This change of the Internet and related ICT elements enabled collaboration among organizations on a larger scale, with partners more loosely coupled and involving distributed networks of collaborators summing up for a more flexible way of conducting business. A composed service is an on-demand and dynamic collaboration between autonomous Web service providers that collectively provide a value added service (Liu, et al, 2011). In terms of timeframe of conducting business it can be short-term or long-term. A Long-term Composed Service (LCS) has a long-term business relation with its users. Examples of LCS can be identified in scientific computing, aircraft industry, travel industry, and automobile industry (Liu, et al, 2011). A typical LCS is an organization that is entirely Web-based, consisting of loose couplings of smaller Web services (Khoshafian, 2006). A LCS is composed of autonomous services specialized in their respective core competencies. This kind of competency specialization and sharing reduces cost and increases quality and efficiency for the LCS. Change management of LCS has been a challenging task because of their complex nature and many elements involved with business processes and affecting relations between business entities making up the LCS. A change management framework for LCS has been proposed in (Liu, et al, 2011). Its business related aspects are illustrative of importance of change management in business initiatives related to the Internet. As presented in Figure 3, it is business related motives that trigger change in this framework. 


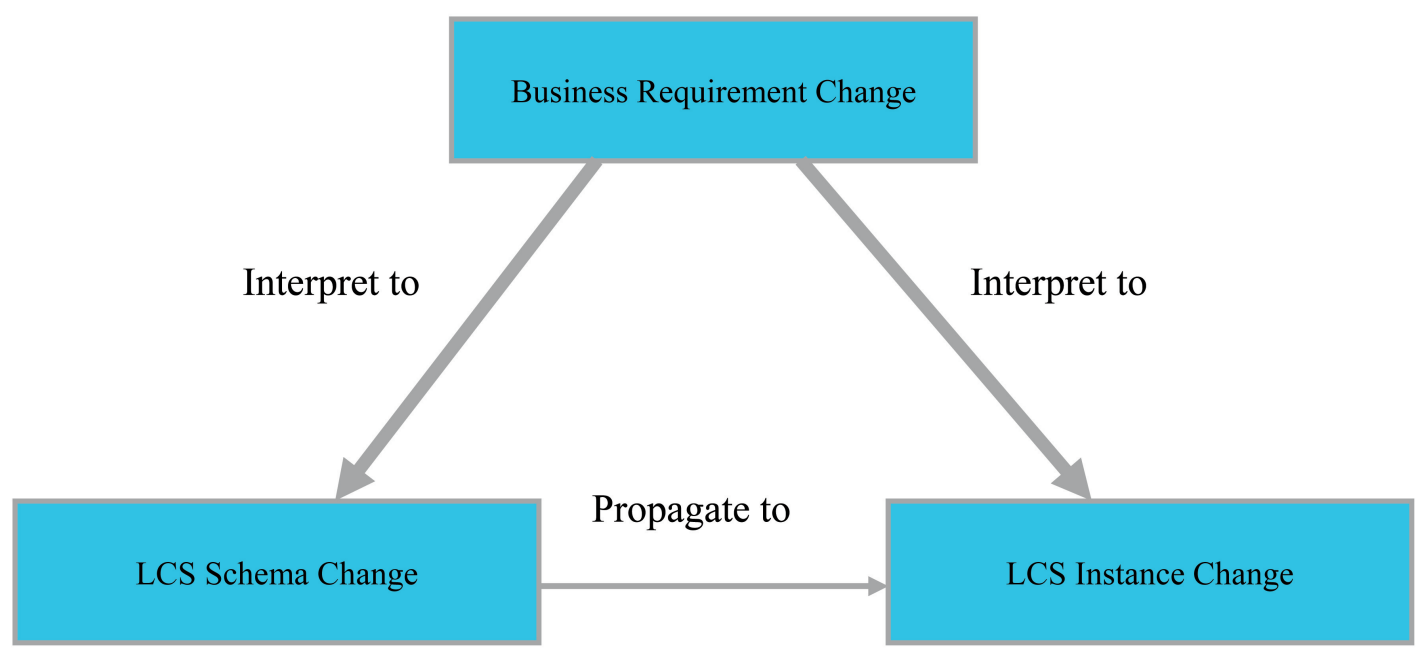

Figure 3: A layer of changes in a LCS,

(Liu, et al., 2011, p. 91)

The changes themselves are ICT related, and business reasoning is interpreted at two instances. The LCS schema represents a more general structure of interconnected ICT functions that make up the essence of distributed LCS structure. The changes affecting it are propagated to instances that represent autonomous ICT services and functions. Here we can see that in a wide range of activities represented by LCS model business and ICT, i.e., Internet reasoning are pushing and pulling each other with a high level of interconnections and causalities driving business logic and decision making into the area of ICT and vice versa.

Another interesting example that illustrates the need for meticulous change management based on thorough evaluation in business operations related to the Internet is provided in the area of ICT unit service management (Spasić, \& Marković, 2013). By using ITIL (Information Technology Infrastructure Library) standards, a set of practices for IT service management (ITSM) that focuses on aligning IT services with the needs of business, management of ICT unit can be made efficient and less prone to problems caused by the Internet and other ICT related changes. Quality implementation of ITIL standards may be an exemplary way to manage the ICT unit and in a broader sense an Internet business Initiative, that are always reliant and by and large executed to a considerable degree by such units. The successful implementation brings the benefits such as alignment of IT services with business goals, comparison with the best players in the field of IT services, risk and IT service cost reduction and creates a steady framework that fosters automation in service management (Spasić, \& Marković, 2013).

One can conclude that all these benefits add to success of a general purpose Internet-related business initiative and thus presented framework is highly relevant to such business ventures.

\section{Conclusion}

New business initiatives are at the core of a successful economy in an era of golobalized, fast changing business world. To successfully lead such initiatives managers need to take special care of change management with the evaluation of ICT environment in targeted markets being one of the important bases for the success of this activity. As the Internet evolves and becomes more than just a medium and a channel of distribution and ever more a strategic factor whose nature determines many aspects of business decision making, new Internet business initiatives become more and more complex to execute while opportunities in this area grow wider daily. To tackle the challenges and explore the opportunities that an evolving Internet presents to businesses worldwide, a strategic approach to ICT needs to be factored in business planning and appropriate methods for evaluating relevant factors need to be applied. 


\section{LITERATURE}

[1] Ashton, K.(2009).That "Internet of Things" thing. RFiD Journal. 22, 97-114.

[2] Bharadwaj, A., El Sawy, O. A., Pavlou, P. A., \& Venkatraman, N. (2013). Digital business strategy: toward a next generation of insights. MIS Quarterly, 37(2), 471-482.

[3] Chih-Lin, I., Rowell, C., Han, S., Xu, Z., Li, G, \& Pan, Z (2014). Toward green and soft: a 5 G perspective, Communications Magazine, IEEE, 52 (2), 66-73.

[4] Choi, Y. K., \& Taylor, C. R. (2014). How do 3-dimensional images promote products on the Internet?. Journal of Business Research, 67(10), 2164-2170.

[5] Cisco, (2011). The Internet of Everything (IoE) Value Index. accessed January 27th 2015 at: http://www.cisco.com/web/about/ac79/docs/innov/loE-Value-Index_External.pdf

[6] Dobrota, M., Jeremić, V., \& Marković, A. (2012). A new perspective on the ICT Development Index. Information Development, 28 (4), 271-280.

[7] Fang, S., Da Xu, L., Zhu, Y., Ahati, J., Pei, H., Yan, J., \& Liu, Z. (2014). An Integrated System for Regional Environmental Monitoring and Management Based on Internet of Things. IEEE Trans. Industrial Informatics, 10(2), 1596-1605.

[8] Gómez-Uranga, M., Miguel, J. C., \& Zabala-Iturriagagoitia, J. M. (2014). Epigenetic Economic Dynamics: The evolution of big internet business ecosystems, evidence for patents. Technovation, 34 (3), 177 189.

[9] International Telecommunication Union (2014). Measuring the Information Society 2014. accessed on January 28th 2015 at: http://www.itu.int/en/ITU-D/Statistics/Documents/publications/mis2014/MIS2014_without_Annex_4.pdf

[10] Kaur, S. (2012). How is "Internet of the 3D Printed Products" going to Affect Our Lives? Pushing frontiers with the first lady of emerging technologies. IETE Technical Review, 29(5), 360-364.

[11] Khoshafian, S. (2006). Service oriented enterprises. Auerbach Publications, Boston.

[12] Liu, X., Bouguettaya, A., Yu, Q., \& Malik, Z. (2011). Efficient change management in long-term composed services. Service Oriented Computing and Applications, 5 (2), 87-103.

[13] McKinsey,(2013). Disruptive Technologies: Advances That Will Transform Life, Business, and the Global Economy, accessed January 29th 2015 at: http://www.mckinsey.com/media/McKinsey/dotcom/Insights\%20and\%20pubs/MGI/Research/Technology\%20and\%20Innovation/Disruptive\%20technologies/ MGl_Disruptive_technologies_Full_report_May2013.ashx

[14] Moran, J., W., \& Brightman, B., K. (2001). Leading organizational change, Career Development International, 6 (2), $111-118$.

[15] Onetti, A., Zucchella, A., Jones, M. V., \& McDougall-Covin, P. P. (2012). Internationalization, innovation and entrepreneurship: business models for new technology-based firms. Journal of Management \& Governance, 16(3), 337-368.

[16] Reaidy, P. J., Gunasekaran, A., \& Spalanzani, A. (2015). Bottom-up approach based on Internet of Things for order fulfillment in a collaborative warehousing environment. International Journal of Production Economics, 159, 29-40.

[17] Rong, K., Hu, G., Lin, Y., Shi, Y., \& Guo, L. (2015). Understanding business ecosystem using a 6C framework in Internet-of-Things-based sectors. International Journal of Production Economics, 159, 41-55.

[18] Sofronijević, A., Milićević, V., \& Ilić, B. (2014). Smart City as Framework for Creating Competitive Advantages in International Business Management. Management, 71.

[19] Sofronijević, A., Milićević, V., \& Ilić, B. (2013). Contemporary management and changes regarding automation of intellectual jobs. Tehnika, 68 (3), 533-538.

[20] Spasić, B., \& Marković, A. (2013). Information and communication technology unit service management in a non-profit organization using ITIL standards. Management-časopis za teoriju i praksu menadžmenta, 18(66), 39-70.

[21] Todnem By, R. (2005). Organisational change management: A critical review. Journal of Change Management, 5 (4), 369-380. 


\section{$1 / 1 / 1 / 1 / 1 / 1 / 1 / 1 / 1 / 1 / 1 / 1 / 1 / 1 / 1 /$ abouthe eathor}

\section{Adam Sofronijević \\ University of Belgrade, University Library Svetozar Marković sofronijevic@unilib.bg.ac.rs}

Adam Sofronijević is a management engineer - master and works at the University Library "Svetozar Marković" of the University of Belgrade. He has written chapters in several scientific monographs and a large number of scientific and professional papers in the field of librarianship, management and IT in domestic and foreign journals. He participates in activities of the Association of European Research Libraries. Adam Sofronijević has many years of managerial experience in the areas of creative industries and digitization.

\section{Vesna Milićević University of Belgrade, Faculty of Organizational Sciences, Serbia milicevic.vesna@fon.bg.ac.rs}

Dr Vesna Milićević is a professor at the Faculty of Organizational Sciences, University of Belgrade where she teaches courses in the areas of business economics, Internet economics, management and international business. She is the author or co-author of a

number of monographs, textbooks and articles in national and international scientific and professional journals. Vesna Milićević is elected member of the Scientific Society of

Economists of Serbia. She has participated in strategic scientific \& research projects and in projects and management training in companies.

\section{Aleksandar Marković \\ University of Belgrade, Faculty of organizational sciences, Serbia}

Aleksandar Markovic is a Full Professor at the Faculty of Organizational Sciences, University of Belgrade, Serbia, where he got his MSc and PhD degrees in the field of

Computer Simulation.Areas of his research include: e-business management, computer simulation, business simulation, business dyinamics.

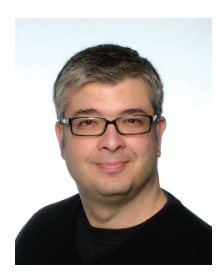
$\mathrm{He}$ is editor in chief of journal Management.
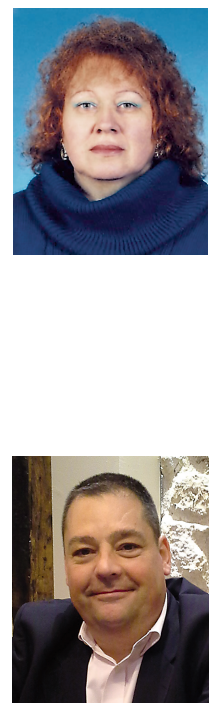